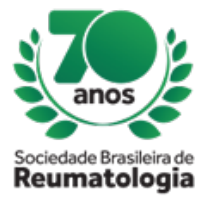

\title{
SLEEP DISTURBANCE IN SPONDYLOARTHRITIS. A CROSS SECTIONAL STUDY IN BRAZILIAN PATIENTS.
}

Andressa S Bertoldi (Hospital Universitário Evangélico Mackenzie, Curitiba, PR, Brasil), Heloisa I Vieira (Hospital Universitário Evangélico Mackenzie, Curitiba, PR, Brasil), Jamile E Mattar (Hospital

Universitário Evangélico Mackenzie, Curitiba, PR, Brasil), Karina R Abrahão (Hospital Universitário Evangélico Mackenzie, Curitiba, PR, Brasil), Betania Longo (Hospital Universitário Evangélico Mackenzie, Curitiba, PR, Brasil), Ana Paula Beckhauser de Campos (Hospital Universitário Evangélico Mackenzie,

Curitiba, PR, Brasil), Juliana Simioni (Hospital Universitário Evangélico Mackenzie, Curitiba, PR, Brasil), Thelma Larocca Skare (Hospital Universitário Evangélico Mackenzie, Curitiba, PR, Brasil)

\section{BACKGROUND}

Background: Spondyloarthritis ( $\mathrm{SpA}$ ) patients may have poor sleep quality that diminish their quality of life. In this context, the sleep disturbance may be associated with awakening in the morning early hours because of inflammatory low back pain and stiffness or with high levels of pro inflammatory cytokines as interleukin (IL)-1 and TNF alpha are involved in the homeostatic regulation of sleep. Also, obstructive sleep apnea (OSA) syndrome seems to be more common in SpA although the reasons are not well understood: it may be due to weight gain because of glucocorticoid use or to compression of the oropharyngeal airway by syndesmophytes in the cervical spine.

Aim: To study the prevalence of sleep disturbance in Brazilians patients with SpA and its association with disease clinical variables.

\section{MATERIALS AND METHODS}

Methods: Cross sectional observational study of 287 individuals (107 with SpA and 108 controls paired for gender, age and body mass index). Patients and controls answered the Pittsburg questionnaire for sleep quality, the Berlin questionnaire for risk of obstructive sleep apnea (OSA) and CES-d (Center for Epidemiological Studies Depression Scale). SpA patients had determination of BASDAI (Bath Ankylosing Spondylitis disease activity index), BASFI (Bath Ankylosing Spondylitis functional index), and VAS (visual analogic scale from zero to ten) for Pain. The charts were reviewed for epidemiologic and treatment data.

\section{RESULTS}

Results: In $43.7 \%$ of patients the sleep was considered poor by Pittsburg scale; 53.2\% had OSA high risk that was higher than controls ( $p=0.005$ and $p<0.0001$, respectively). Pittsburg scale values associated with BASDAI $(p=0.0004)$, VAS of pain $(p=0.01)$, BASFI $(p<0.0001)$ and CES-D $(p<0.0001)$. No differences were noted when axial forms were compared to peripheric disease (Pittsburg with $p=0.82$ and Berlin questionnaire with $p=0.77)$. Multiple regression showed that BASFI $(p=0.01)$ and BASDAI $(p=0.01)$ were independent variables.

\section{CONCLUSION}

Conclusions: There is a high prevalence of sleep disturbance in SpA patients that correlates with disease activity, pain, function and depression. Peripheric and axial diseases are equally affected. 